Seminar Paper No. 285

THE POLITICAL ECONOMY OF LEVIATHAN

by

Ronald Findlay

and

John D. Wilson

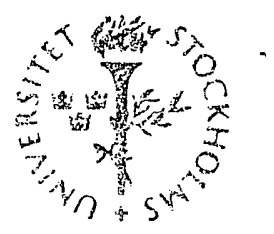

IRSTITUTE FOR INTERNATIONAL ECONOMC STUDIES

Unversity of Stockholm 
ISSN $0347-8769$

Seminar Paper No. 285

THE POLITICAL ECONOMY OF LEVIATHAN*

by

Ronald Findlay

and

John D. Wilson

* Presented at the Third Pinhas Sapir Conference on "Economic Policy in Theory and Practice" in memory of Abba P. Lerner, Te1-Aviv, May 28-31, 1984.

Findlay's work on this paper was mostly done while visiting the Institute for International Economic Studies in Stockholm. We would like to thank participants in seminars at Maryland, Stockholm, Gothenberg, Lund, Uppsala, Helsinki and Tel-Aviv for very helpful comments.

Seminar Papers are preliminary material circulated to stimulate discussion and critical comment.

August, 1984

Institute for International Economic Studies

S-106 91 Stockholm

Sweden 


\section{The Political Economy of Leviathan}

The theory of the state is something that most economists have been content to leave to the political scientists. When the state does appear in economic analysis it usually does so in one or the other of the following roles. One is as a benign and omniscient authority that obligingly imposes taxes, bounties or other measures at just the right level to off-set some "distortion" in the price mechanism, due say to externalities of one sort or another, so as to assure Pareto-efficiency of market outcomes. This aspect of the state in economics is particularly pronounced in what may be called the Pigou-Meade tradition in welfare economics, which has dominated the modern developments of public finance and international trade. The other, dramatically opposed role of the state in standard economic analysis, is as the culpable or innocent tool of malevolent special interests, that instead of correcting distortions à la Pigou and Meade is the very source of them, e.g. minimum wage or usury laws, rent control, tariffs and so on. Conservative economists denounce these interventions on both equity and efficiency grounds, while liberals are apt to be apologetic, sympathizing with real or alleged distributional objectives but usually pointing out that alternative (not always feasible) measures could be used that would achieve these goals at a lower cost in efficiency.

The analysis of special interests and pressure groups has recently become quite a popular past-time among economists, as for instance Becker (1983) and Findlay and Wellisz (1982), following the lead of pioneers such as Anthony Downs (1957), Mancur 0lson (1965) and Gordon Tullock (1967). The "rent-seeking" model 
of Krueger (1974) fits into this framework and has indeed provided an umbrella term to cover all of this sort of analysis, as in the recent volume edited by Buchanan, et al. (1980). ${ }^{1}$ Another earlier term denoting this approach is of course "public choice", the name of a distinguished journal that has been appearing since the late sixties. Much of the substance of this analysis has been expounded in a lucid and balanced way by Mueller (1979), while Frey (1978) represents a merging of this approach with some independent European traditions and concerns.

The "predatory" view of the nature of the state has perhaps received its fullest expression to date in a recent work by Brennan and Buchanan (1980). For them the state is a Leviathan that preys on its citizens, with an insatiable appetite for revenue that it consumes for its own sake. The authors devote much ingenious analysis to the "taming" of the revenue-gobbling monster by means of "fiscal constitutions" that limit the powers of the state to tax, spend and issue debt.

The economic historian Douglass North has protested vigorously against the tendency by writers in the "public choice" tradition to ignore the "productive" view of the state, which of course has a long and distinguished tradition in the economic literature going back at least to the Staatsbildung of the Mercantilists. Adam Smith himself, in his famous "duties of the sovereign", compiled a rather extensive list of necessary and desirable public functions, ranging from defense and law and order to education and canals. No one other than an anarchist or extreme libertarian would contest that there is an essential productive role for the state, without which the price mechanism 
itself could not work effectively. The trouble is that we take law and order, enforcement of contracts and so on for granted and do not acknowledge the necessity of government at the outset. The standard neoclassical approach has been to consider the private economy exclusively to begin with, assuming away the necessity of resources to be allocated for the "organization" of the market system itself, and then only introducing the government to take care of particular public goods by a diversion of production from a "private" sector, the maximal level of productivity of which is quite independent of any public goods at all. Our intention in this paper is to present a simple minimal model of "productive" government, in which the allocation of resources between the public and private sectors is determined endogenously in a system that includes behavioral hypotheses about the agents exercising the power of the state to tax and spend. At the same time as we allow a "productive" role for the state we also examine the possibilities of "predatory" behaviour as we11. In our view the state as an institution is intrinsical1y both "productive" and potentially "predatory" in character, and our intention is to try to capture this dual character in a simple general equilibrium model. Hobbes' Leviathan was a monster, but he did say that before the rule of the Leviathan, in the state of nature, life was "solitary, poor, nasty, brutish and short". Economists, of all people, should not forget that there are no free lunches, and the price for relief from the state of nature may often be high. How rapacious the Leviathan is depends on what he is trying to maximize and as we shall see there is no commanding unique answer to that question. 
Thomas Carlyle, who hated the economists of his day, derided their theory of the state as "anarchy plus the constable". The economists of our day, for the most part, have even left out the constable from formal models of general equilibrium, of whatever level of mathematical sophistication. The very raison d'etre of the theory is to determine resource allocation between competing uses endogenously. Thus the state can only be accommodated in the usual framework by assuming that it requires either negligible resources, or that the required resources are "subtracted" from the available pool before the analysis of markets begins, which is entirely contradictory to the spirit of general equilibrium analysis.

We propose the following simple model. Let "real national income", conceived as a Hicksian composite commodity $\mathrm{Y}$, be

$$
\mathrm{Y}=\mathrm{A}\left(\mathrm{L}_{\mathrm{g}}\right) \mathrm{F}\left(\mathrm{L}_{\mathrm{p}}, \overline{\mathrm{K}}\right)
$$

with

$$
L_{g}+L_{p}=\bar{L}
$$

where $\mathrm{L}_{g}$ and $\mathrm{L}_{\mathrm{p}}$ are labor employed in the government and private sectors respectively, $\overline{\mathrm{L}}$ is the fixed total of available labor and $\overline{\mathrm{K}}$ is the fixed capital of the private sector. ${ }^{2}$ We assume that

$$
A^{\prime}\left(L_{g}\right)>0, A^{\prime \prime}\left(L_{g}\right)<0, \quad A(0)=1
$$

while the function $F$ is homogeneous of the first degree in $L_{p}$ and $\mathrm{K}$. When $\mathrm{L}_{\mathrm{g}}$ is zero, $\mathrm{i}_{\bullet} \mathrm{e}$. there is no government at all, we are 
in the Hobbesian state of nature and the "life of man" is described by his famous string of adjectives. Thus $F\left(L_{p}, \bar{K}\right)$ is the level of real output achievable under anarchy. Once there are "constables", i.e. $\mathrm{L}_{\mathrm{g}}$ is positive, real output can be higher since $\mathrm{A}\left(\mathrm{L}_{\mathrm{g}}\right)$ with $\mathrm{L}_{\mathrm{g}}>0$ will be greater than unity. This can only be achieved, however, by reducing $L_{p}$, so that $F\left(L_{p}, \bar{K}\right)$ itself is lower. Thus it is possible to determine the distribution of the fixed labor force $\overline{\mathrm{L}}$ between $\mathrm{L}_{\mathrm{g}}$ and $\mathrm{L}_{\mathrm{p}}$ that maximizes Y. This is easily done by maximizing ( 1 ) subject to (2) and obtaining as the necessary first order condition that

$$
F A^{\prime}\left(L_{g}^{*}\right)=A\left(L_{g}^{*}\right) F_{L}\left(L_{p}^{*}\right)
$$

where the asterisks indicate the optimal levels of $\mathrm{L}_{g}$ and $\mathrm{L}_{\mathrm{p}}$ and $F_{L}$ the partial derivative of $F$ with respect to $L_{p}{ }^{\cdot}$ It is natural to interpret the left-hand side of (4) as the marginal productivity of a government worker and the right-hand side as the marginal productivity of a worker in the private sector. The requirement for optimality is that these two marginal productivities be equated.

Denoting the left and right hand sides of (4) by $\underline{x}$ and $\underline{y}$ respectively we have

$$
\frac{d x}{d L_{g}}=F A^{\prime \prime}\left(L_{g}\right)-A^{\prime}\left(L_{g}\right) F_{L}<0
$$




$$
\frac{d y}{d L_{p}}=A\left(L_{g}\right) F_{L L}-A^{\prime}\left(L_{g}\right) F_{L}<0
$$

In Figure 1 the horizontal axis represents the fixed labor force $\bar{L}$, with $L_{g}$ measured from 0 and $L_{p}$ from $0^{\prime}$. The negatively sloped curves depict $\underline{x}$ and $\underline{y} s$ functions of $\mathrm{L}_{g}$ and $\mathrm{L}_{\mathrm{p}}$ respective$1 y$, the reasons for the negative slopes being established by (5) and (6). The intersection of the two curves at $G$ determines $L_{g}^{*}$ as $\mathrm{OH}$ and $\mathrm{L}_{\mathrm{p}}^{*}$ as $\mathrm{O}^{\prime} \mathrm{H}$.

With perfect mobility of the homogeneous labor pool between employment in government and the private sector, and competitive factor markets in the latter the real wage in the "optimal" allocation is indicated by the equal distances $O W$ and $0^{\prime} W^{\prime}$ on the vertical axes. The curves $x\left(L_{g}\right)$ and $y\left(L_{p}\right)$ show the marginal productivities of labor in the government and private sectors for each allocation of labor represented by the corresponding point on the horizontal axis. Each of the curves $x\left(L_{g}\right)$ and $y\left(L_{p}\right)$ thus diminishes both because there is more labor in the sector itself (the usual diminishing returns effect) and because there is less labor in the other sector. The curve $\mathbb{M M}^{p}$ that cuts $y\left(\mathrm{~L}_{p}\right)$ at $G$ is the marginal productivity of labor curve in the private sector corresponding to a fixed allocation of labor to the government sector at the optimal level $\mathrm{L}_{\mathrm{g}}^{*}$. It thus lies below $\mathrm{y}\left(\mathrm{L}_{\mathrm{p}}\right)$ at $\mathrm{L}_{\mathrm{p}}<$ $L_{p}^{*}$ and above $y\left(L_{p}\right)$ at $L_{p}>L_{p}^{*}$. The wage-bill in the government sector, equal to total government expenditure, is indicated by the area OWGH. The wage-bill in the private sector is $0^{\prime} W^{\prime} G H$ while the shaded area under $\mathrm{MM}^{\prime}$ and above $\mathrm{GW}^{\prime}$ represents the "profits" or "rents" in the private sector, i.e. the competitively imputed returns on the fixed factor $\overline{\mathrm{K}}$. The area GMHO' is equal to $Y$, the total output of the private sector. 
National income, as conventionally measured, is equal to $Y$ plus the "output" of the government sector, which is the wage-bill OWGH in that sector.

Since there is no market for government "output" it of course has to be financed by taxation. One possible scheme is by a simple proportional tax $\underline{t}$ on the output of the private sector, Y. The real wage in the private sector after tax then becomes the real wage that the government has to pay. The tax rate necessary to exactly finance the optimal employment $\mathrm{L}_{\mathrm{g}}^{*}$ in government can be computed from the condition that

$$
\left(1-t^{*}\right) \mathrm{AF}_{\mathrm{L}} \mathrm{L}_{\mathrm{g}}^{*}=\mathrm{t}^{*} \mathrm{Y}^{*}
$$

i.e. government employment times the competitive wage equals the yield from $t^{*}$ levied on the maximum output $\mathrm{Y}^{*}$ in the private sector. From this it follows that

$$
t^{*}=\frac{\lambda}{(1+\lambda)}
$$

where $\lambda \equiv \frac{L_{g}^{*}}{L_{p}^{*}} \cdot \frac{A_{L} L\left(L_{p}^{*}\right) L_{p}^{*}}{Y^{*}}$

Making the reasonable assumption that $L_{g}^{*}\left\langle L_{p}^{*}, \lambda\right.$ is a fraction of the share of labor in the output of the private sector. The tax burden is shared between workers and "capitalists" in the private sector proportionally to their shares in output.

In terms of Figure 1 the real wage in both sectors is uniformly reduced from $w^{*}$ to $\left(1-t^{*}\right) w^{*}$, with $L_{g}^{*}$ and $L_{p}^{*}$, and therefore $\mathrm{Y}^{*}$, unchanged. In Figure 2 we plot government revenue 
and expenditure as functions of $\mathrm{L}_{\mathrm{g}}$, with the tax rate as $t^{*}$. The revenue function reaches a maximum when $\mathrm{L}_{\mathrm{g}}=\mathrm{L}_{\mathrm{g}}^{*}$ while the expenditure function is monotonically increasing, as can be seen by differentiating the left hand side of (7) with respect to $\mathrm{L}_{\mathrm{g}}$, and cuts the revenue function from below at the point where it reaches a maximum at $\mathrm{L}_{\mathrm{g}}=\mathrm{L}_{\mathrm{g}}^{*}$. Thus the optimal solution is achieved by setting the tax rate at $t^{*}$ and having the government hire labor competitively until the budget is exactly balanced. Government employment in excess of $\mathrm{L}_{\mathrm{g}}$ will result in deficits and less than $\mathrm{L}_{\mathrm{g}}$ in surpluses so the balanced budget "rule" at tax rate $t^{*}$ generates the optimal solution as the only possible one for the government.

Note that the output tax is not distortionary in our simple model since it is simply shifted back on to the two factors, both of which are in perfectly inelastic supply. 
II

In the previous section we have indentified the "optimal" level of government for our simple model and a possible method for its financing. We now turn to the basic problem with which we started which is the behavior of a purely self-interested "Leviathan". We must now identify the creature in some way, since merely to say that it maximizes its own "utility" in some sense is vacuous without the specification of the appropriate utility function. We do not believe that there is a unique answer to this question in view of the extreme variety of historical state systems. Our procedure will be to consider two major alternatives that appear to be of interest.

As the first case let us consider an absolute Ruler or Sovereign, who might be conceived as a King or Sultan as in earlier times, or a contemporary Dictator. We assume that the Sovereign is constrained by a historically given tax rate on the output of the private sector that he cannot alter. Subject to this tax rate, however, he has full powers to decide the level of employment in the public sector and hence, indirectly, the national income. He is also constrained to pay the public employees at lest the same wage as they can earn in the privte sector, i.e. there is no corvée or conscription permitted.

Under the circumstances it would be "rational" for the Sovereign to maximize the "surplus" which we define as

$$
S \equiv t Y\left(L_{g}\right)-(1-t) A F_{L} L_{g}
$$

The Sovereign will thus set $\mathrm{L}_{g}$ at such a level as to maximize the difference between the revenue and the expenditure, 
taking into account the interdependence between the two, due to the labor constraint (2). Differentiating (10) with respect to $L_{g}$ and taking account of (2) we obtain as a necessary condition for maximizing $S$

$$
F A^{\prime}\left(L_{g}\right)=A F_{L}+\frac{(1-t)}{t}\left(A^{\prime} F_{L}-A F_{L L}\right)
$$

Since the second term on the right hand side is positive we obtain the result that the Sovereign will employ less government workers than the socially optimal level $\underset{g}{L^{*}}$ determined by (4). The reason for this result is clear. The Sovereign being interested in the surplus of revenue $t Y\left(L_{g}\right)$ over expenditure $(1-t) \mathrm{AF}_{\mathrm{L}} \mathrm{L}_{\mathrm{g}}$ he equates marginal revenue to the marginal cost of hiring more government workers, which is exactly what (11) says. He has no incentive to achieve the "optimal" level of public employment for society, $\mathrm{L}_{\mathrm{g}}^{*}$, since this would yield him less than the maximum surplus obtainable.

In Figure 3 we plot the revenue and expenditure of the government as functions of public employment $\mathrm{L}_{g}$, with $\mathrm{L}_{\mathrm{p}}$ being equal to $\bar{L}-L_{g}$ and the wage in the public setor being equal to $(1-t) \mathrm{AF}_{\mathrm{L}}$. The tax rate $t$ for which Figure 3 is drawn is arbitrary, including $t^{*}$ of the previous section as a possibility. The surplus-maximizing Leviathan will choose public employment as $\tilde{L}_{g}$, in keeping with (11), which is less than $L_{g}^{*}$, the point at which $Y^{*}$ and $t Y^{*}$ are maximized. $\tilde{Y}$ is the level of output corresponding to $\tilde{\mathrm{L}}_{\mathrm{g}}$.

If we denote the maximized surplus that the Leviathan swallows as $\tilde{S}$ the citizens can then consume $(\tilde{Y}-\tilde{S})$. By citizens 
we mean property owners in the private sector and workers in both public and private employment. It is of course true that

$$
(\tilde{Y}-\tilde{S})<Y^{*}
$$

the level of consumption that the citizens could enjoy if the Leviathan were to altruistically provide optimal government at zero cost. But Hobbes would say that the Leviathan is not bound by the social contract to do this. All that the citizens have a right to expect is that

$$
\tilde{(Y}-\tilde{S})>Y_{0}
$$

where $\mathrm{Y}_{0}$ is the level of output in the "state of nature". So long as (13) is satisfied the citizens are benefited by the rule of the Leviathan and have a corresponding obligation to obey.

It is apparent from (11) that how close $\widetilde{Y}$ is to $\mathrm{Y}^{*}$ depends on the level of the prameter $\underline{t}$, with $\tilde{\mathrm{Y}}$ approaching $\mathrm{Y}^{*}$ as $\underline{t}$ approaches unity. This does not mean, of course, that the interest of the citizens is better served the higher is the tax rate, since they only consume $(\widetilde{Y}-\widetilde{S}$ ) and not $\widetilde{Y}$, and $\widetilde{S}$ also will be an increasing function of the tax rate. Thus there will be some "optimum" tax rate for the citizens, between zero which is the "state of nature" and unity that attains $\mathrm{Y}^{*}$ but at the price of too high a surplus for the Leviathan. This problem will not be investigated here though it is one of considerable interest.

The fact that the Leviathan is constrained by a given tax rate is realistic, since even the absolute monarchs of early modern Europe generally could not raise tax rates without the 
consent of parliaments and other representative assemblies of the nobility and the people. Modern dictators are no less constrained by fears of riots and revolts. ${ }^{3}$

In the Hobbesian view, which is the one that we have taken, the state is a "natural monopoly" and the "surplus" as we have defined it is a sort of monopoly "rent" that the Sovereign can enjoy. The alternative Lockean view sees the exercise of governmental power as being a more conditional or "competitive" process, in which the citizens as it were "auction" the right to rule over them to the highest bidder. ${ }^{4}$ In spite of the criticism of historians of political thought, it is difficult not to identify Hobbes' view with someone who lived through the English Civil War of the sixteen forties, and Locke's with that of the so-called "Glorious Revolution" of 1688 in which the English people deposed James II, with his pretensions to "divine right", and replaced him with the "limited" or "constitutional" monarchy of Mary and William of Orange.

In 1984, of all years, it is difficult to consider the problem of the Leviathan to be that it provides too little government. Surely the fear today is the opposite, that civil liberty and private initiative are threatened by an excess of government. How can this be accounted for in our mode1?

The link between the surplus-maximizing Leviathan and the obtrusive Orwellian Leviathan of today is provided by the growth of bureaucracy. From being the obedient tools of absolute monarchs bureaucracies have evolved into monolithic institutions in their own right, Frankenstein monsters that have somehow got out of control. The "rent-seeking" hypothesis of Anne Krueger 
(1974) provides a convenient framework into which to place our discussion, though it is much wider in scope than her original paper which only considered the limited problem of import quotas in less developed countries.

The $\tilde{\mathrm{S}}$ that the Sovereign enjoys, as we have said, is a kind of monopoly rent that he can spend on palaces, mistresses and other luxuries. The actual administration of government, however, is likely to be, and historically generally was, in the hands of professional specialists, originally colorful figures such as Wolsey and Richelieu but increasingly the grey, faceless tribe of today. We thus postulate, in the fashion of Krueger, that the rent $\tilde{S}$ originally enjoyed purely by the Sovereign attracts a horde of office-seekers anxious to get their hands on some of it. The heads of the bureaucracies, for empire-building rasons made familiar by the writings of Parkinson, Niskanen (1971) and others, would not be averse to this. In keeping with these ideas we propose the following Parkinson-Niskanen Law:

"Government expenditure expands to absorb all the revenue available to finance it".

Aplication of the Law to Figure 3 indicates that equilibrium will be attained at the level of public employment corresponding to $\hat{L}_{g}$, with revenue $t \hat{Y}$ entirely absorbed in the wages (at competitive rates) of the $\hat{\mathrm{L}}_{g}$ workers, with employment in the private sector at $\left(\overline{\mathrm{L}}-\hat{\mathrm{L}}_{\mathrm{g}}\right)$. We assume that the exogenous tax rate $t$ is sufficiently high so that $\hat{\mathrm{Y}}<\mathrm{Y}^{*}$ in spite of the fact that $\hat{\mathrm{L}}>\mathrm{L}_{\mathrm{g}}^{*}$ i.e. the public sector is too large relative to the 
optimal levels associated with $L_{g}^{*}$ and $\mathrm{Y}^{*}$. If $\underline{t}$ were sufficiently lower, the dissipation of the surplus $\tilde{\mathrm{S}}$ could have brought the economy closer to $\mathrm{Y}^{*}$, with the expenditure function crossing the revenue function to the left of $\mathrm{L}_{\mathrm{g}}^{*}$ and $t \mathrm{Y}^{*}$. The case that we have chosen, of $t$ greater than $t^{*}$, is what corresponds to the "1984" image of an overly bloated bureaucratic Leviathan. The citizens no longer have a Sovereign who enjoys a glittering Court, financed by $\tilde{\mathrm{S}}$, at their expense. It is still, however, entirely possible for

$$
\tilde{(Y}-\tilde{S})>\hat{Y}
$$

for the same parameters $t, \overline{\mathrm{K}}$ and $\overline{\mathrm{L}}$. A faceless bureaucracy, without any conspicuous "privileged" consumption, can nevertheless result in a lower level of welfare for the citizens than an absolute monarchy with all its trappings.

Unlike the monarchical Leviathan, however, the bureaucratic Leviathan can in principle be tamed. If the exogenous tax rate prameter were to be set at $t^{*}$, the "optimal" level of the previous section, then the Parkinson-Niskanen process will lead to exactly $L_{g}^{*}$ workers in government service and output of $Y$. The bureaucracy is permitted just that amount of revenue as will lead to the optimal level of government employment and expenditure, at competitive wage-rates with the private sector. This is the "Proposition 13" approach.

If the bureaucracy could manipulate the tax rate itself, however, then it is easy to see that government expenditure would be carried beyond the social optimum. In Figure 4 we show the 
level of output $\mathrm{Y}$ in the private sector as a function of the tax rate $\underline{t}$, with the distribution of employment for each tax rate, and hence $\mathrm{Y}$, being determined by the Parkinson-Niskanen process at that tax rate. $Y$ reaches a maximum $Y^{*}$ at $t^{*}$ and thereafter declines for higher values of $t$. The budget-maximizing bureaucracy would be best off at the maximum revenue point, where $t Y(t)$ is at a maximum. This will clearly be on the negative side of the function $Y(t)$, where its elasticity is equal to minus unity. The collective self-interest of the bureaucracy therefore always results in tax rates, public employment and competitive wage-rates that are above the socially optimal levels.

Though we have discussed the surplus-maximizing and bureaucratic Leviathans as alternative cases they can also be regarded as the limiting cases of a continuous spectrum. Intermediate cases correspond to some positive but less than maximum surplus being enjoyed by some elements in the society. In addition to the royal "Court" that we have considered it could be benefits for the sick and aged and other handicapped groups, as in the modern "welfare state". Another possibility is salaries for the bureaucracy at higher than competitive levels, with entry restricted by some device such as the famous examination system for Chinese mandarins or the modern British Oxbridge variant. Ironically, such "rent-keeping" devices can be socially beneficial in our model, since they prevent the "rent-seeking" entry of workers from the privte sector where their social productivity is higher though their private earnings are less.

One of the problems with "welfare state" dispositions of the "surplus" is that they tend to lend themselves to bureau- 
cratic proliferation in administration, that swallows up the surplus itself while reducing output in the private sector. "Feudal" rather than "democratic" ways of disposing of the surplus are probably more of a bulwark against Parkinsonian encroachments.

Finally, we may note that "property" in our model will favor limited government, while "labor" will be in favor of any expansion of the public sector that is feasible. The latter proposition follows simply from the fact that diverting workers from private to public employment at competitive wage-rates always increases the wage-rate and hence the wage-bill since total employment is fixed. The wage-rate $\underline{w}$ is $(1-t)\left(A\left(L_{g}\right) F_{L}\right.$ and

$$
\frac{d w}{d L}=(1-t)\left[A^{\prime} F_{L}-A F_{L L}\right]>0
$$

The qualification to this statement that "labor" will always favor expansion of the public sector is that part of the "surplus" may be enjoyed by labor as a whole or by some segments of it. In this case there may be resistance to an expansion of the public sector that dissipates this disposition of the surplus. 5

The result that "property" will favor only a limited extent of government is also easy to establish. Total profits after tax, denoted $R$, are $(1-t) A\left(L_{g}\right) F_{K} \bar{K}$ and

$$
\frac{d R}{d L_{g}}=(1-t) \bar{K}\left[A^{\prime} F_{K}-A F_{K L}\right]=0
$$


defines the optimal extent of the public sector for "property" as the point where the additional profit generated by public employment at the margin $(1-t) A^{\prime} F_{K} \bar{K}$ is equal to the loss due to the contraction of employment in the private sector which is $(1-t)$ $\mathrm{AF}_{\mathrm{KL}} \overline{\mathrm{K}}$.

Thus we have a natural coalition between government bureaucracy and "labor" to expand the public sector and between the owners of real "property" and "rights" to the disposition of the surplus to limit it. The changing social balance of power between these groups could be a significant hypothesis in accounting for the "growth of government" in modern society that many observers have noted. Peltzman (1980) and Meltzer and Richard (1981) put forward interesting models to account for this phenomenon in terms of voting on redistributive transfers. Our approach here in terms of an over-expansion of a productive government sector may be complementary to these contributions. 
III

The ideas behind the simple model that we have examined in this paper have an ancient lineage but at the moment are perhaps most closely associated by economists with two major recent works, by Brennan and Buchanan (1980) and North (1981). In this final section we make a brief attempt to relate our model to their work and that of some others. We of course have no intention to try to provide a detailed examination and critique of their very rich and diverse views, a task that would be extremely rewarding but quite beyond the scope of this paper.

Brennan and Buchanan consistently adopt a "constitutional" perspective throughout their book. Their view is that the basic fiscal structure of a state should be elevated above the messy arena of interest group politics in a pluralist democracy, since for all the reasons that have been extensively investigated in the public choice literature the outcomes of such processes are likely to be extremely inefficient. They also have no faith in the benign and omniscient intervention of a Bergson-Samuelson or Pigou-Meade planner. Their view is the classical liberal one that it is only prudent for a citizen to assume that he will be governed by rascals rather than saints, and that he should consequently choose to live under a system of rules that will oblige the rascals in power to act in the citizens' interest rather than their own, wherever that is possible. Hence they adopt the hypothesis that the state is a Leviathan in a "minimax" spirit, i.e. minimize the maximum damage that a malevolent state can do to you. 
Throughout most of their book the authors adopt the hypothesis that the Leviathan maximizes revenue. They say that this is equivalent to maximizing the surplus if public expenditure is fixed and the level of revenue is independent of the level of expenditure. The one exception is in chapter 7, where they consider a problem in which the Leviathan's ability to obtain revenue is made conditional by the citizens on the provision of public goods. It is thus only in this chapter that they consider surplus maximization proper, in the manner of our investigation here. While Niskanen and other writers on bureaucracy are frequently referred to by the authors, they do not distinguish sharply as we have done between the divergent analytical consequences of the surplus-maximizing and budget-maximizing hypotheses about the behavior of the Leviathan. Their model in chapter 7 is strictly partial equilibrium in character and does not consider the interdependence between the public and private sectors explicitly as we have done. Furthermore, the state in our model raises the productivity of the private sector itself, through the provision of the indispensable framework of law and order without which the enforcement of contracts and so on would be difficult if not impossible. While they are presumably not anarchists, the reader does get the impression that the state in their view is a pure predator on the body politic, like the Mongols or the Mafia.

Douglass North, on the other hand, has stressed the fact that the state is an indispensable institution for the very possibility of civilization and economic progress, in spite of the fact that ruling groups have undoubtedly been motivated in 
their actions to generate and preserve the rents associated with their control of this particular natural monopoly. The very insightful and suggestive sketch of "A Neoclassical Theory of the State" in chapter 3 of North's book has been an important source of inspiration for our work. Our contribution has been to incorporate very similar ideas into a simple but explicit general equilibrium model.

Our model also links up with the work on the expansive tendencies of bureaucracies by Niskanen (1971), Borcherding (1977) and others and represents a start in linking the more specific concerns of that literature to an analysis of their interaction with the economy as a whole. The we11-known study by Bacon and Eltis (1976) on Britain's economic problem as being one of "too few producers" is related to our discussion of how the Parkinson-Niskanen process can take the economy beyond the "optimal" level of public employment. Bacon and Eltis appeal to the Classica1-Physiocratic distinction between "productive" and "unproductive" labor in their distinction between "marketed" and non-marketed" output sectors. This terminology is somewhat misleading and unnecessary. It is not that public servants or "non-marketed" output suppliers are "unproductive" in any absolute sense, according to our model, but that this sector, for the reasons given, has expanded excessively at the expense of the other. 
To conclude, we may note that the analysis is capable of extension in a number of directions. An obvious one is to investigate the comparative statics of shifts in parameters of the model as it stands. The production technology can be made considerably more general, for instance by introducing capital as well as labor into government acivities, leading to a model with many of the features of the Heckscher-Ohlin-Samuelson model in the theory of international trade. Nationalization, or the "public provision of private goods" can also be introduced. Government borrowing and public debt, money and seigniorage are other possibilities. Most interesting of all, perhaps, would be to endogenize the tax rate by an explicit modelling of the various pressure groups identified in the paper, along the lines of Findlay-Wellisz (1982) and other work in that area.

Ronald Findlay

John D. Wilson 
FOOTNOTES

1) Bhagwati (1982) is an extensive taxonomic survey of this literature on what he prefers to call "directly unproductive profit-seeking (DUP) activities".

2) Either or both of these factor supplies could readily be made into functions of their after-tax returns. In view of the extensive analysis of the effects of taxes on factor supplies we have thought it better to simplify by abstracting from these we11-known considerations.

3) Alternatively we could of course have let the tax rate be chosen by the Sovereign, while at the same time making factor supplies respond negatively to higher taxes.

4) As Yoram Weiss has commented such a procedure would make the Sovereign choose the "optimal" level of public employment for society, since he would then be maximizing $\mathrm{Y}$ minus a constant, which is his "bid" for the right to rule. If the bidding were competitive the citizens could enjoy a"least cost" government. The possibility of such arrangements in practice, at the national level, is of course another question.

5) The result that labor will favor an extension of government would also hold if "capital" were to be used in the government sector as we11, provided that it is relatively more labor-intensive than the private sector. 


\section{References}

Bacon, Ro and W. Eltins, Britains Economic Problem: Too Few Producers, Macmillan, 1976.

Becker, G. S., "A Theory of Competition Among Pressure Groups for Political Influence", Quarterly Journal of Economics, August, 1983.

Bhagwati, J. N. " Directly Unproductive, Profit-seeking (DUP) Activities". Journal of Political Economy, October, 1982.

Borcherding, T. E. (ed.), Budgets and Bureaucrats: the Sources of Government Growth, Duke University Press, 1977.

Brennan, G. and J. M. Buchanan, The Power to Tax, Cambridge Univeristy Press, 1980 .

Buchanan, J. Mo et al. (eds.), Towards a Theory of the Rent-Seeking Society, Texas A\& M University Press, 1980.

Downs, A., An Economic Theory of Democracy, Harper, 1957.

Findlay, R. and S. Wellisz, "Endogenous Tariffs, the Political Economy of Trade Restrictions and Welfare", in J. N. Bhagwati (ed.) Import Competition and Response, University of Chicago Press, 1982 .

Frey, B., Modern Political Economy, Wiley, 1978.

Krueger, A. O., "The Political Economy of the Rent-Seeking Society", American Economic Review, June, 1974.

Meltzer, A. and S. Richard, "A Rational Theory of the Size of Government", Journal of Political Economy, October, 1981.

Mueller, D., Public Choice, Cambridge University Press, 1979. 
Niskanen, W., Bureaucracy and Representative Government, Aldine, 1971.

North, D., Structure and Change in Economic History, Norton, 1981.

01son, M., The Logic of Collective Action, Harvard University Press, 1965.

Peltzman, S., "The Growth of Government", Journal of Law and Economics, 1980 .

Tullock, G., "The Welfare Costs of Tariffs, Monopolies and Theft", Western Economic Journal, June 1967. 


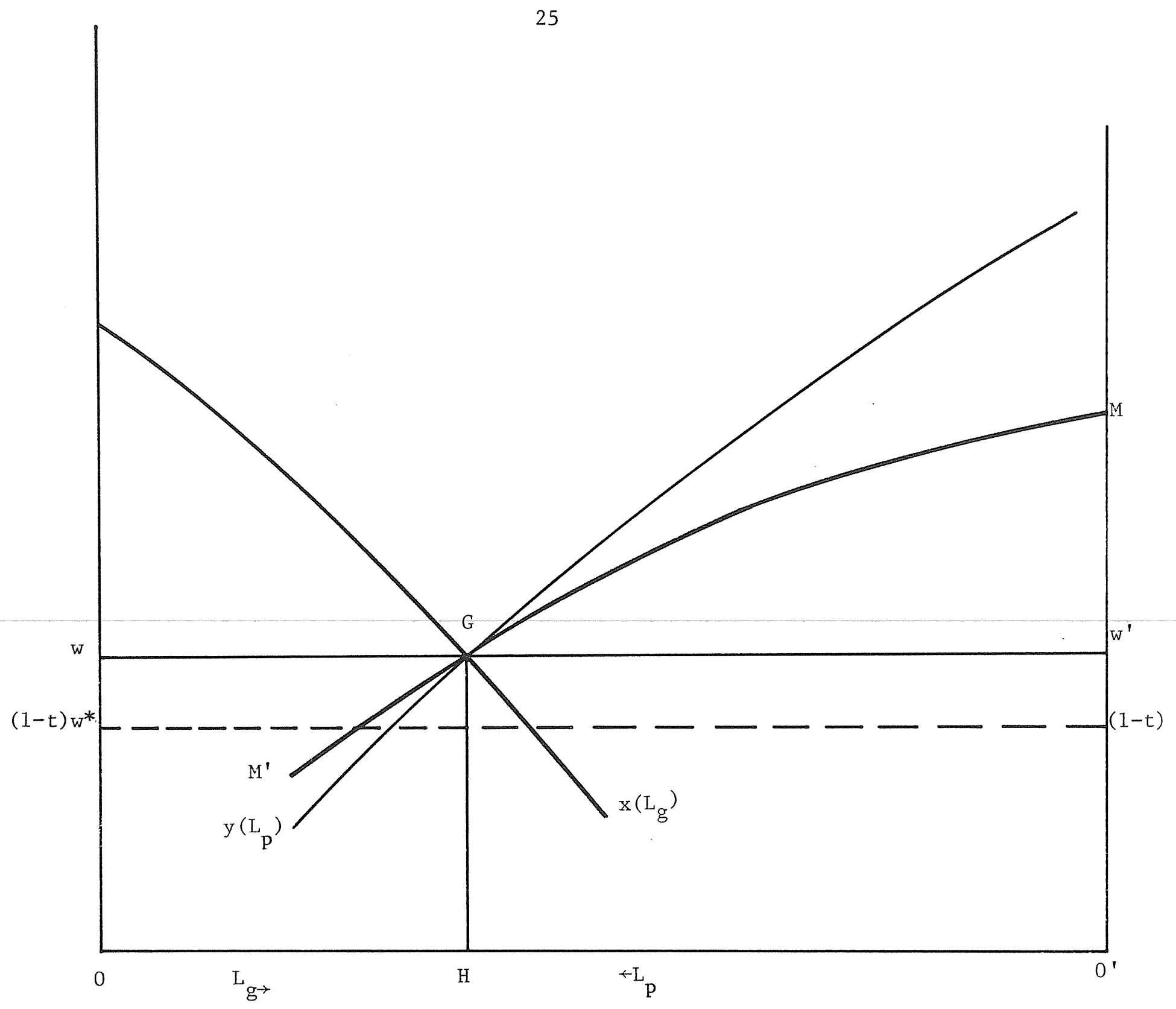

Figure 1 


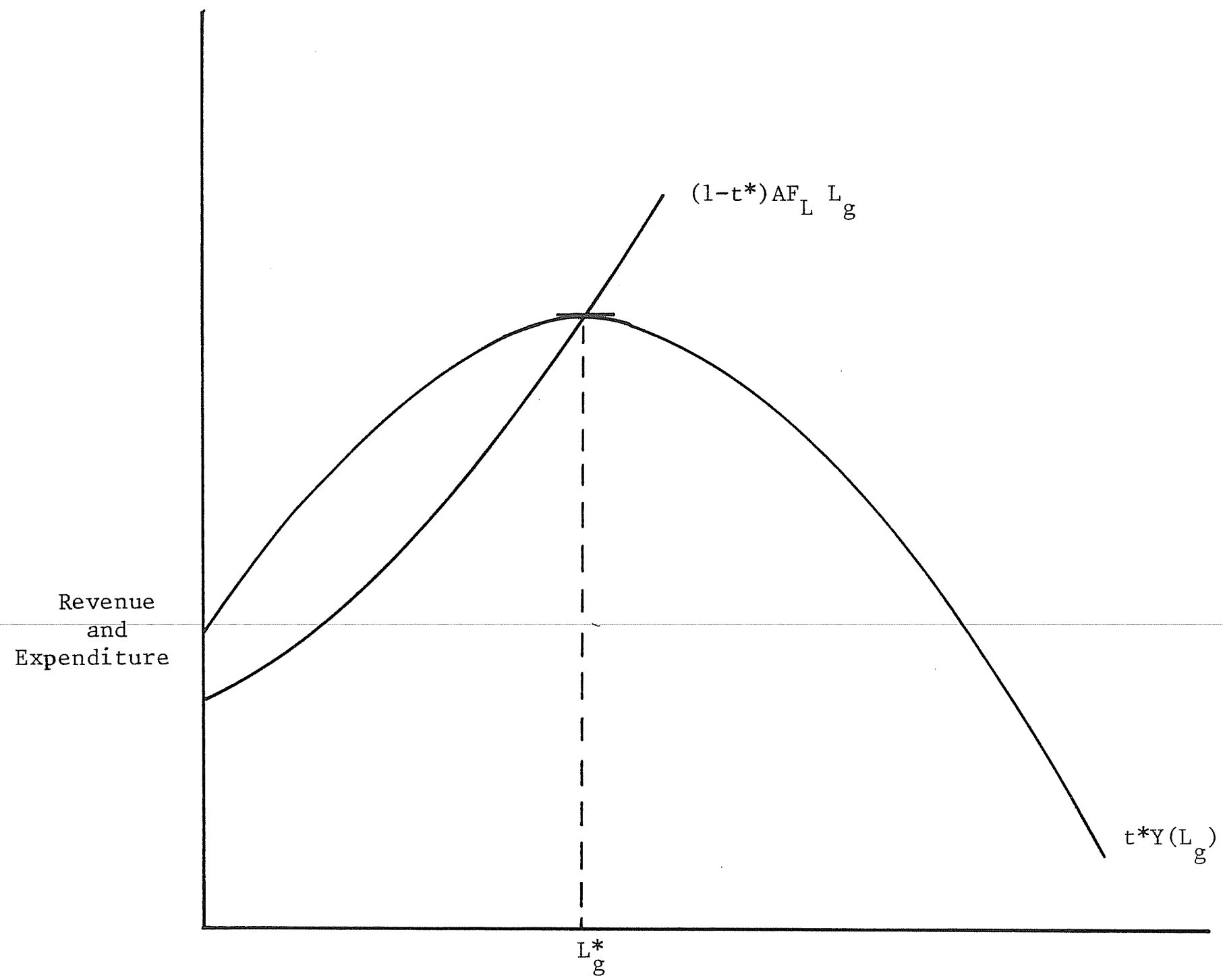

Public Employment

Figure 2 


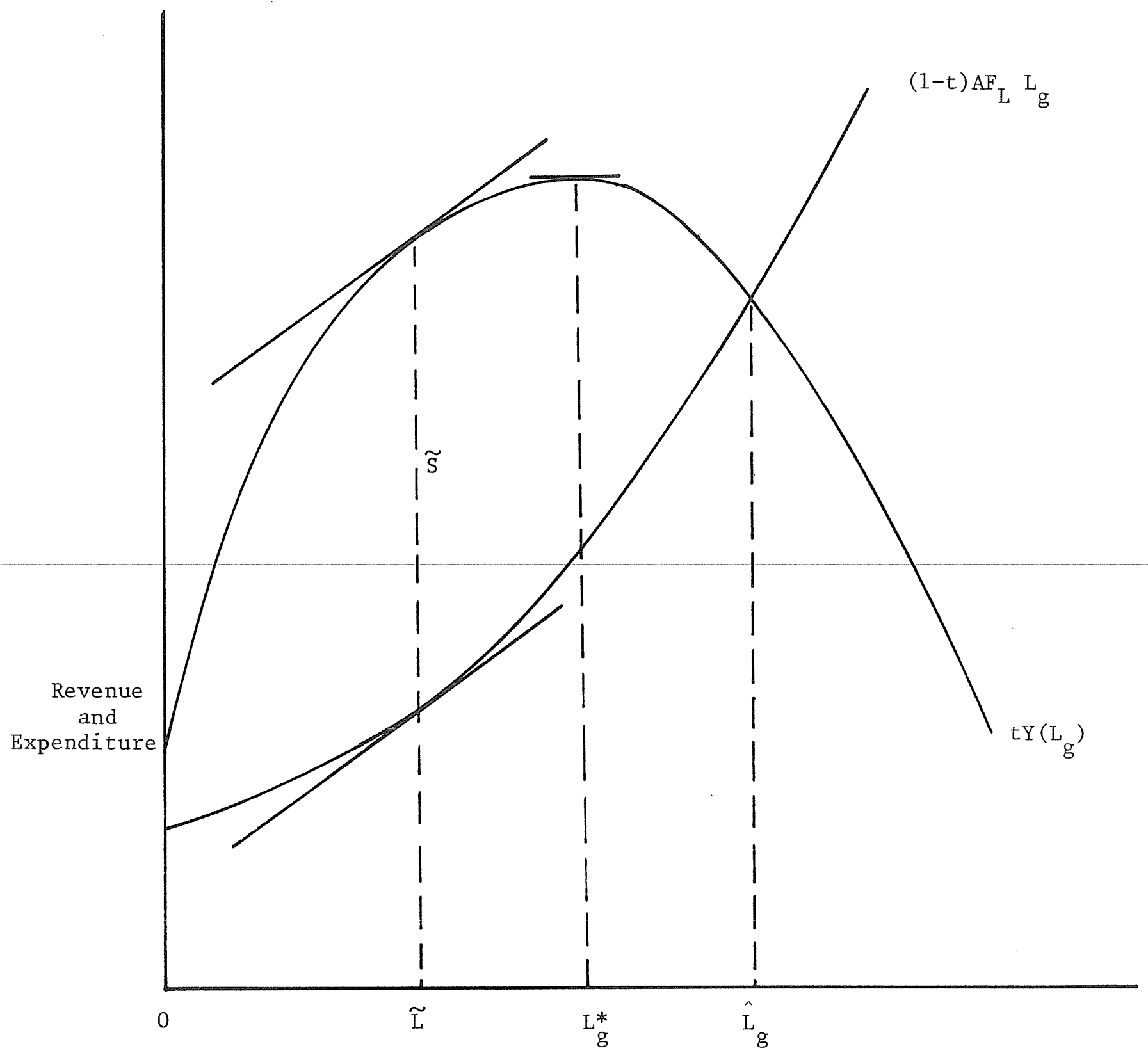

Figure 3 


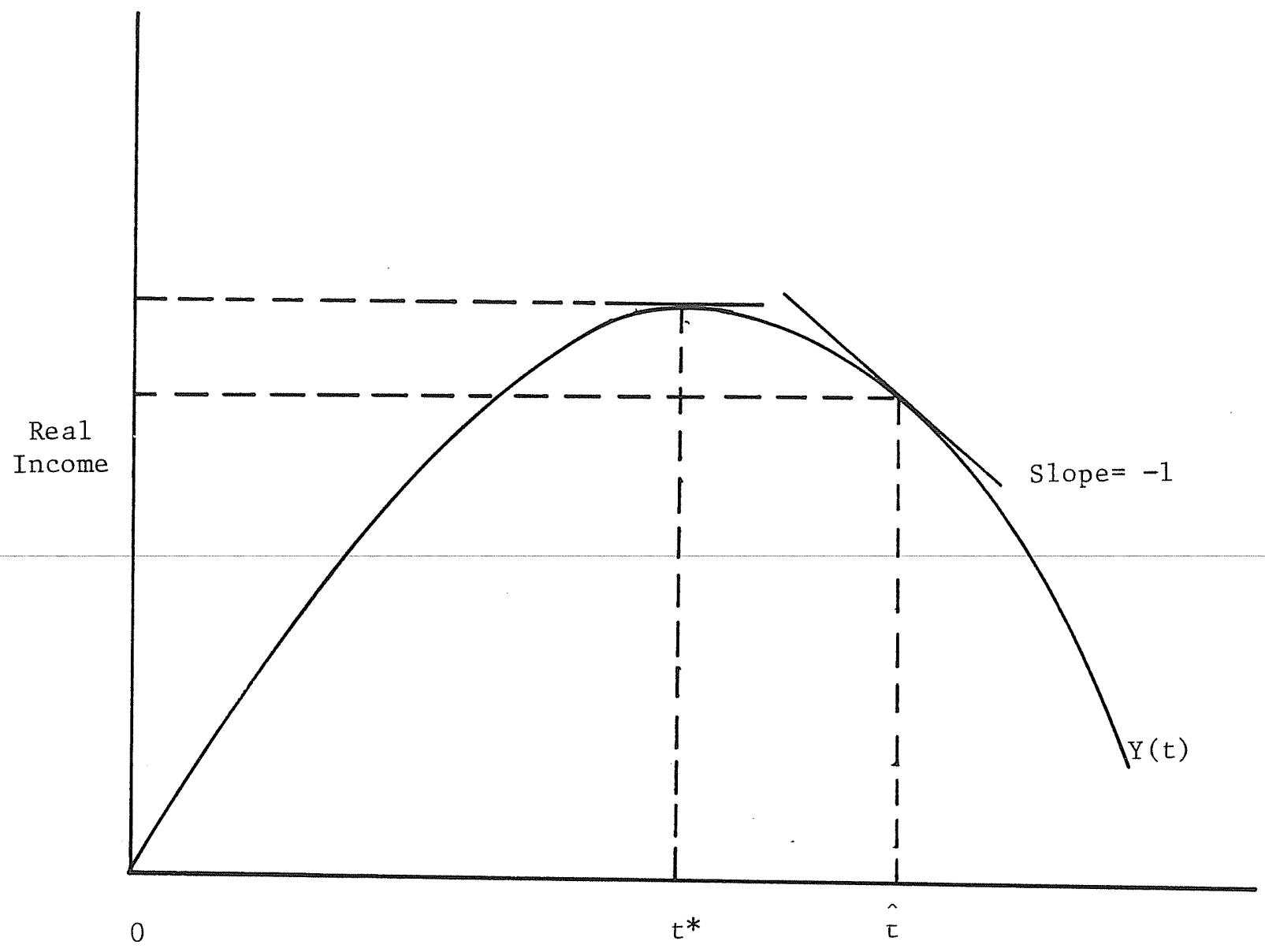

Tax Rate

Figure 4 